\title{
Concerns of poor quality of life should not deprive patients of the opportunity of curative surgery
}

\section{K McManus}

\section{Is it worth undergoing lung cancer resection and the resulting poor quality of life when the survival outcomes are not good?}

$\mathrm{P}$ ostoperative pain and breathlessness following lung cancer surgery are important causes of disability. The prospect of such symptoms may influence the decision to proceed with surgery. Incapacitating intercostal neuralgia, unlike other surgical pain, often does not go away. Intolerable breathlessness caused by removing lung tissue from a patient who already has poor lung function can result in severe limitation of exercise tolerance. Is it really worth it when the survival outcomes in lung cancer are so poor anyway?

A surgeon's main interest is radical clearance of the tumour and long term survival of the patient. Success is judged in terms of operative mortality and 5 year survival. The referring physician, on the other hand, may perceive that the patient will be left physically and emotionally handicapped by surgery and refer him or her for chemotherapy or radiotherapy instead, even though there is little evidence that these treatments are less debilitating and cure rates are known to be lower. What price does the patient pay for radical surgery?

In this issue of Thorax Myrdal et al compare quality of life (QoL) in lung resection patients with a normal population and a group of matched patients undergoing coronary artery bypass grafting (CABG). . Lung resection necessarily removes functioning lung tissue; CABG supposedly improves the function of the heart. Despite this, postoperative QoL was comparable in the two study groups, except for the single subdomain of physical function where patients with lung cancer performed worse, as expected. Both groups deviated from the normal population in all domains except, surprisingly, body pain. Despite having a serious malignancy and undergoing major surgery, neither social function nor mental health status were impaired in patients with lung cancer.

A common feature of QoL studies is that patients with lung cancer start from a level significantly lower than the normal population before surgery. They deteriorate further at 3 months but scores return to the preoperative level by 12 months..$^{2-5}$ Handy et al $^{2}$ found persistent low scores at 6 months which may account for their rather pessimistic conclusion. The current study, with a median follow up of 23 months, is more optimistic.

Relatively few patients are left with respiratory impairment or are housebound by lung cancer resection. The cardiorespiratory impairment which results in such severe debilitation also predisposes to perioperative complications. Surgeons factor this into their calculations in preoperative assessment. $\mathrm{Pa}$ tients who survive to contribute to QoL studies have already selected themselves by surviving the surgery. Further selection occurs in the first months after surgery with non-cancer deaths due to cardiopulmonary complications.

The physical scores reflecting pain, fatigue, dyspnoea, and sleep disturbance are those most often reported as deteriorating after surgery. The loss of lung tissue understandably contributes to dyspnoea on exertion but not in a predictable fashion. A study from our own institution showed that neither thoracotomy alone nor limited lung resection affected exercise capacity and the effect of pneumonectomy was not as great as might have been predicted. ${ }^{6}$ Volume alone is not the predictive factor as removal of emphysematous lung may actually improve performance, compensating for removal of functioning lung. ${ }^{7}$ A functional measure such as predicted carbon monoxide transfer factor seems to be a more accurate predictor of postoperative dyspnoea. ${ }^{2}$

Postoperative pain is time dependent. Much of the early pain is due to contusion of the intercostal nerves by retractors at the time of surgery and will predictably take a 6-18 month course. This can be reduced by modern surgical and anaesthetic techniques. Most studies report that video-assisted thoracoscopic surgery (VATS) reduces pain after resection, although only a few surgeons perform VATS for lobectomy or pneumonectomy. ${ }^{8}$ VATS has taught thoracic surgeons that pain management, both acute and chronic, can be improved by careful attention to technique. In open surgery it is possible to protect the intercostal nerve, reduce splaying of the ribs, and reduce rib fractures. Epidural analgesia, intercostal nerve block (either static or infusion), and phrenic nerve blockade all contribute to reduced perioperative pain. Avoiding perioperative pain may reduce the perception of late intercostal neuralgia.

The psychology of the lung cancer patient is more difficult to assess. The various QoL instruments try to tease out the relevant factors but they may not be able to overcome the fact that the survivors whom we study after lung cancer surgery are the "chosen few". They belong to the $10 \%$ who have qualified for surgery in the first place. They have then survived the operation and, if they are one of the $35 \%$ of surgical candidates who survive to 5 years, they are members of the exclusive "lung cancer survivors club". This probably contributes to the good relative scores on emotional and social parameters even when the physical scores are low.

Patients who undergo lung resection do have poorer QoL than the normal population, but these patients start with reduced QoL parameters before surgery. Physical function is reduced but improves over 12 months. Postthoracotomy pain is not the imposing threat we have feared in the past. Perceived changes in QoL should not be a deterrent to lung resection for non-small cell lung cancer, despite the fact that it is major surgery with known morbidity.

Thorax 2003;58:189

\section{Author's affiliation}

K McManus, Consultant Thoracic Surgeon, Royal Group of Hospitals, Belfast BT12 6AB, UK; mactheknife@utvinternet.com

\section{REFERENCES}

1 Myrdal G, Valtysdottir S, Lambe M, et al. Quality of life following lung cancer surgery. Thorax 2003;58: 194-7

2 Handy JR Jr, Asaph JW, Skokan L, et al. What happens to patients undergoing lung cancer surgery? Outcomes and quality of life before and after surgery. Chest 2002; 122:21-30.

3 Dales RE, Belanger R, Shamii FM, et al. Quality-of-life following thoracotomy for lung cancer. J Clin Epidemiol 1994;47: 1443-9.

4 Mangione CM, Goldman L, Orav EJ, et al. Health-related quality of life after elective surgery: measurement of longitudinal changes. J Gen Intern Med 1997; 12:686-97.

5 Zieren HU, Muller JM, Hamberger U, et al. Quality of life after surgical therapy of bronchogenic carcinoma. Eur J Cardiothorac Surg 1996;10:233-7.

6 Nugent A-M, Steele IC, Carragher AM, et al. Effect of thoracotomy and lung resection on exercise capacity in patients with lung cancer Thorax 1999;54:334-8.

7 Anderson KL. Change in quality of life after lung volume reduction surgery. Am J Crit Care 1999;8:389-96

8 Sugiura H, Morikawa T, Kaji M, et al. Long-term benefits for the quality of life after video-assisted thoracoscopic lobectomy in patients with lung cancer. Surg Laparosc Endosc Percutan Tech 1999;9:403-8. 